\title{
ENTRE MINEIROS, SENHORES DE TERRA E O ESTADO: ALIANÇAS DAS MONTANHAS NOS ANDES SUL PERUANOS (1930-2012)
}

Guillermo Salas Carreño-Pontificia Universidad Católica del Perú

Comentando sobre os protestos sociais contra investimentos em mineração, que ocorreram por volta de maio de 2011 no departamento de terras altas de Puno, o então presidente Alan García criticou a demanda das comunidades para que não se incluísse o vulcão Khapia na concessão de mineração. As comunidades tomavam o vulcão como um apu (senhor), uma entidade provedora de fertilidade, detentora de agência e intencionalidade.

"[Nós] temos que vencer as ideologias panteísticas absurdas que acreditam que as paredes são deuses [...] Voltar para aquelas formas primitivas de religiosidade onde as pessoas dizem 'não toque naquela montanha porque é um apu, é cheio do espírito milenar do 'eu não sei o quê', certo? Bom, se aceitamos que então não devemos fazer nada, nenhuma mineração [... . Eu acho que precisamos de mais educação, mas isso é um trabalho de longo prazo ". (Garcia 2011)

Muitas críticas seguiram essas declarações. Por exemplo, Gamio(2011)elaborou como o discurso do presidente viola os princípios da democracia liberal quando ele "qualifica ofensivamente como 'ideologias absurdas' as crenças dos povos das terras altas nos Apus". Ele adiciona "autoridades políticas deveriam se abster de interferir nos aspectos espirituais da vida dos cidadãos que envolvem suas crenças pessoais sobre o bem superior e o divino". Outros também apontaram como García desprezou a religiosidade andina enquanto apoiando completamente outras religiões, quando alega, na mesma entrevista, que as almas dos ancestrais não poderiam residir em uma montanha, mas antes no paraíso (e.g. Chirif 2011).

Não obstante, as práticas pelas quais os povos das terras altas se engajam com as montanhas não podem ser reduzidas a "crenças religiosas", como Gamio e García, de formas diferentes, assumem. Primeiramente, como experimentado pelos indígenas montanheses, apus são as próprias montanhas, seres materiais e não espíritos. Segundo, sua capacidade de agência não é uma questão de crença, mas antes fatos sobre como o mundo é. Montanhas agentes não podem pertencer ao "sobrenatural", nem podem ser reduzidas a "natureza". Elas são, em seus distintos modos, membros cruciais da sociedade. As declarações de García mostram como estes mundos indígenas são largamente simultâneos e profundamente envolvidos em relações complicadas com aqueles fundados no trabalho da purificação: o estrito policiamento da separação entre a natureza previsível e a agente sociedade humana que é o núcleo dos mundos modernos (Keane 2007; Latour 1993).

Existe uma literatura crescente que explora os limites das noções modernas de realidade quando em face de ontologias que não se conformam com a separação de reinos como natureza e cultura, material e imaterial, ciência e 
política. Estes diferentes esforços almejam construir caminhos para visibilizar e traduzir as múltiplas realidades que coexistem com os mundos modernos dominantes (e.g. Blaser 2009; De la Cadena 2010, 2011; Chakrabarty 2000; Descola 2005; Latour 2011; Viveiros de Castro 2004). Levando em consideração essa literatura, tento historicizar a presença das montanhas como atores sociais dentre os mundos Quechua da região de Cuzco (Peru) durante o século $\mathrm{XX}$, particularmente em suas relações com representantes de estado, senhores de terra e corporações mineiras.

Primeiro, o artigo apresentaum panorama para caracterizar as sociedades Quechua que incluem lugares agentes. Segundo, discute os modos pelos quais montanhas se relacionam com companhias mineiras e comunidades locais no contexto do boom da mineração associado às reformas neoliberais dos anos noventa e os altos preços dos metais. Como elabora De la Cadena (2010), e as palavras de García exemplificam, montanhas agentes estão crescentemente se fazendo presente nas esferas públicas e política formal andinas. Não obstante, o comportamento político de montanhas não é um fenômeno recente. Assim, o artigo busca historicizar como montanhas interagem com burocratas do estado, senhores de terra, e comunidades Quechua dos anos trinta até o presente boom da mineração.

A heterogeneidade da sociedade da região de Cuzco não pode ser reduzida a uma simples dicotomia. Não se tratam de dois grupos claramente diferentes (indígenas/ não indígenas) diretamente associados a óbvias diferentes ontologias, mas antes uma larga multiplicidade de construções ontológicas produzidas por processos históricos particulares em contexto local. Essa diversidade envolve uma grande familiaridade com práticas provenientes de outras ontologias. As práticas de endereçar agência a montanhas não é segregada a populações rurais falantes de Quechua. A maioria dos citadinos que tomam a si mesmos como mestizos conhecem, e muito deles participam ativamente, das práticas que entendem lugares como pessoas (De la Cadena 2011; Salas 2012: 12-17).

Este trabalho é embasado pelo acervo etnográfico das terras altas de Cuzco e arredores, e por minha experiência de campo. Uso de informações que advém de uma visita à mina de Tintaya no ano 2000, bem como de conversas com Juan de Dios Huillca, em 2002. Ele é um curandero urbano que trabalha em San Jerónimo, nos arredores da cidade de Cuzco. Adicionalmente, entre 2007 e 2009, conduzi intensa pesquisa etnográfica na cidade de Cuzco e na comunidade Quechua de Hapu (Paucartambo).

Este artigo não pretende investigar modos indígenas de construção de memória coletiva (e.g. Abercrombie 1998), antes, conforma com uma concepção normativa de história e sua concomitante naturalização do tempo seculare vazio. Da mesma maneira que, em muitos trabalhos antropológicos, agentes não humanos acabam confinados ao reino das crenças culturais; na história, as alegações dos povos sobre as intervenções não contam como válidas explicações para eventos sociais (Chakrabarty 2000). Ao invés de analisar quais são as "reais" explicações por trás das assertivas das pessoas sobre a intervenção de agentes não humanos, procurei fazer visível como diferentes povos Quechua, em diferentes momentos do século XX, experimentaram a intervenção de montanhas como atores sociopolíticos. Assim, eu parto por enquadrar essas práticas como sendo solidariedade social durkheimiana, ou projeções alienantes de Marx, mas como formas de engajamento com seres que existem em um diferente-ainda que simultâneo - mundo real. Como qualquer exploração de outros mundos, este é um exercício de tradução inerentemente ligado ao equívoco. Seguindo 
Viveiros de Castro (2004), estes não devem ser entendidos como equívocos entre diferentes visões do mesmo mundo, mas visões de diferentes mundos simultâneos.

Enquanto que a maioria das etnografias dos Andes do Sul do Peru ou das terras altas bolivianas elaboram como os povos indígenas inscrevem agências às montanhas, pedras, ou qualquer outro aspecto distintivo da paisagem (Allen 1988; Fuenzalida 1980; Isbell 1978; Martínez 1983; Morote 1956; Ricard 2007; Sallnow 1987), apenas poucos discutem como estes seres são relacionados politicamente a senhores de terra, instituições estatais ou atores políticos. Apesar de enquadrá-las como mitologia, um artigo pioneiro de Earls (1969) foca como montanhas são relacionadas com a burocracia do Estado. Outros autores que, de diferentes maneiras, discutiram como montanhas eram pensadas como atores políticos, ou intervindo em processos políticos mais amplos, são Ansion (1984), Gose (1994), David Gow (1980), Rosalind Gow (1982) e Nash (1979). Em termos de historicizar o comportamento das coisas, Gose (2008) propõe que "o culto aos espíritos das montanhas" surgiu de formas anteriores de veneração ancestral durante a segunda metade do século XVIII, assim fazendo um argumento semelhante com este artigo: que estes seres se relacionam diferentemente com as pessoas de acordo com as mudanças históricas do horizonte político. Para os fins deste artigo, um caminho central pelo qual meu argumento se devia do de Gose é que eu considero que estes seres não são espíritos, mas as próprias montanhas.

\section{SOCIEDADES DE HUMANOS E LUGARES}

Nesta seção introduzo brevemente um panorama que elaborei em trabalhos anteriores para compreender a relação entre pessoas e montanhas. Então introduzo mais considerações para o propósito deste texto.

Nas sociedades Quechua de Cuzco, relações sociais entre humanos e os lugares em que eles vivem e trabalham são construídas sobre exatamente os mesmo princípios pelos quais as relações sociais entre humanos o são. Todas as formas de interação social pressupõem noções de circulação de alimento e níveis de coabitação. Estão presentes em todas as interações entre todos os tipos de seres que podem ser inscritos com sociabilidade. Lugares nomeados são indivíduos sociais e são atribuídos de pensamento, capacidades de ação, emoções, e intenções de todos os tipos - a habilidade de continuar as relações ou de desprezá-las - e - com a capacidade material certa - a habilidade de nutrir ou destruir. Locais são provedores de alimento e abrigo para os humanos através de sua materialidade. Crucialmente, é a materialidade das montanhas que está em jogo quando se preparam operações de mineração. A vida humana depende totalmente da generosidade das montanhas - usualmente masculinas e chamadas como apus (senhores) - e das terras cultiváveis e habitadas - femininas e chamadas como pachamamas (mães-terra). O reconhecimento humano da dependência aos lugares é expresso em diferentes formas de lhes dar alimento. Doenças, uma safra ruim, ou qualquer outro infortúnio resultam de não alimentar adequadamente ou negligenciar comida a algum lugar. Assim, deveria ser claro que as relações entre pessoas específicas e locais específicas não são necessariamente harmoniosas. Por estas redes de nutrição e coabitação, seres humanos e seres lugares mostram-se como seres agentes constituintes das sociedades Quechua (Mannheim \& Salas 2013; Salas 2012: 133-170). 
nominados são propriamente agentes nos mundos Quechua. Os campos relacionais que constituem comunidades particulares de humanos e lugares estão situados em relações sociais e espaciais mais amplas. Se relacionamento é inscrito em uma maior sociedade regional, nacional, e global, constituída de pessoas bem como de lugares maiores e mais abrangentes. Esse relacionamento é também inscrito em um processo histórico vasto, incluindo o da nação e além.

Lugares que não são alimentados por humanos rotineiramente pode ser muito perigosos. Harris (1980: 80-81) caracteriza estes seres danosos que usualmente não são transitados, onde não há cultivo, e onde não há comida doada rotineiramente, como selvagens. Gose (1994: 217) associa essa selvageria com as próprias montanhas. Não obstante montanhas podem ser vistas como selvagens de uma perspectiva humana. Como muitos etnógrafos reportaram, enquanto lugares estão permanentemente interagindo com seres humanos, eles também têm seu próprio mundo social: possuem gêneros, podem ser ricos ou pobres, podem possuir grandes rebanhos, têm amizades e inimizades. Por exemplo, Juan de Dios comentou que quando consumem oferendas de comida (ver Dalle 1969; Fernández 1997), convidam seus parentes e colegas para consumirem as oferendas juntos. Ele também me contou como, por exemplo, Pikul e Tawqaray - os apus de distritos rivais em Cuzco, San Jerónimo e San Sebastián, possuem uma antiga animosidade. A menor altitude de Tawqaray seria devido aos golpes passados de Pikul da mesma forma que uma grande marca de deslizamento de terra em Pikul foi provocada por um arremesso de Tawqaray (ver também Morote 1956: 294).

O poder e a esfera de influência das entidades estão usualmente associados a sua altitude. Quanto mais alta for a montanha, mais forte é seu poder e maior sua esfera de influência, englobando todos lugares que podem ser vistos de sua altura. Assim, vivem em uma ordem hierárquica que tende a ser icônica da burocracia hierárquica do Estado (Allen 1988; Ansion 1984; Gose 1994: 211; Morissette \& Racine 1973: 170-1; Morote 1956: 294; Roel 1966: 27 ).

Suas hierarquias são também associadas com uma qualidade fractal, conquanto é possível achar mais e mais nomes dentre um determinado lugar nominado. Um lugar pode assim conter muitos outros lugares e eles podem conter mais, tudo dependendo do contexto social e espacial no qual as pessoas podem se referir aos lugares (e.g. Favre 1967: 122). Cada local particular tem sua esfera de influência que é subsumida naquela de um maior e mais poderoso. Logo, existem lugares poderosos, vastamente mais poderosos que humanos comuns, e que assim recebem atenção privilegiada enquanto outros não. Durante minhas conversas sobre estas entidades com don Luis, um paqu de Hapu, ele mencionou diversas vezes como, assim como humanos, os apus possuem mulas, galinhas, e gatos, mas os humanos os veem como vicunhas, condores, e pumas (ver também Rosalind Gow \& Condori 1976; Morote 1956; Roel 1966). Este arranjo lembra o perspectivismo amazônico proposto por Viveiros de Castro (1998): humanos e animais possuem a mesma cultura, mas cada espécie vive em um mundo diferente. Ao passo que lugares possuem uma cultura similar com aquela pertencente aos humanos, sua natureza é radicalmente diferente daquela dos humanos, e assim, não é surpreendente que os humanos não podem ver ou se engajar facilmente com o mundo social dos lugares. Essa é a extensão das similaridades entre as comunidades Quechua de Cuzco e o perspectivismo amazônico. Para as onças na 
Amazônia, o sangue humano não pode ser outra coisa que não cerveja de mandioca (Viveiros de Castro 2004), já nos termos Quechua, os lugares podem transcender seu próprio mundo social e observar e entender a sociedade humana por uma perspectiva humana. Desta forma, lugares intervêm deliberadamente em assuntos humanos, e punem ou recompensam pessoas de acordo com seus critérios mais oumenos opacos. Comotal, omundo dos lugares compreende e transcende o entendimento humano, falando das hierarquias presentes nas relações entre pessoas e lugares.

\section{MONTANHAS E COMPANHIAS MINERADORAS}

A mineração no Peru mostrou um crescimento impressionante desde meados dos anos noventa: a superficie destinada à exploração de minerais aumentou de quatro milhões a aproximadamente vinte e quatro milhões de hectares entre 1993 e 1997 (De Echave 2005: 10). Isso continuou devido aos altos preços dos metais e o forte apoio do estado neoliberal (Bebbington et al. 2008). Não obstante, instituições estatais têm sido notoriamente ausentes em mediar as relações entre as companhias mineradoras e as comunidades locais (Revesz \& Diez 2006). Sendo assim, não é surpreendente que a atividade mineradora encontrou forte oposição das comunidades rurais e têm se tornado a principal causa de protestos sociais na área rural peruana. "Conflitos socioambientais" somaram cinquenta por cento dos duzentos e quarenta e oito conflitos reportados pelo Ombudsman peruano em julho de 2010 (Defensoría-delPueblo 2010: 6). Os números correspondentes para junho de 2012 são de sessenta por cento de duzentos e quarenta e sete conflitos (Defensoría-del-Pueblo 2012: 10).

Até recentemente, Cuzco não fora uma grande região de mineração se comparada com, por exemplo, Cerro de Pasco. A minha de Tintaya, localizada na província de Espinar, é a única mina aberta em Cuzco. Começou suas operações em 1985 como uma companhia estatal, foi privatizada em 1996, e atualmente é propriedade de Xstrata. Tintaya logo irá se exaurir, e as instâncias mineiras do governo central autorizaram Xstrata a começar a exploração do grande depósito de Antapaccay, apenas a dez quilômetros de Tintaya (um investimento de \$1.47 bilhão). Las Bambas é outra mina aberta de propriedade de Xstrata que está em construção (Investimento de $\$ 4.2$ bilhões) nas províncias de Cotabambas e Grau (departamento de Apurimac), vizinhas da província Chumbivilcas, de Cuzco (Xstrata, 2012). Embora existam outras operações, como as minas de Anabi e Ares em Chumbivilcas, as atividades da Xstrata somam oitenta e oito por cento da produção mineradora em Cuzco (Viale 2011).

Existem outros grandes projetos a serem implantados em Cuzco. Hudson Bay Minerals começará a operar a mina Constancia (Chumbivilcas, investimento de \$1.5 bilhão) em 2015 (HudBay 2013), e Pan Pacific Mining também o fará com a mina Quechua (Espinar, investimento de \$970 milhões) em 2014 (Bloomberg 2011). Adicionalmente, a forte exploração mineral está sendo levadaa cabo em toda a região. $78 \%$ da província de Chumbivilcas, $48 \%$ de Paruro, $34 \%$ de Espinar e 25\% de Anta foram inclusos em concessões de exploração em novembro de 2010 (CooperAcción 2010).

Os protestos das comunidades têm enfrentado níveis alarmantes de violência das forças do Estado. Em maio de 2012, as comunidades de Espinar, perto do lançamento do projeto de Antapaccay, demandavam maiores contribuições 
da Xstrata para fundos de desenvolvimento comunal, mudanças na forma como os fundos eram administrados, bem como mudar o escopo do balanço ambiental. Frente a meses de inação do governo, e o desinteresse da companhia em negociar, essas demandas transformaram-se em protestos que foram violentamente reprimidos pela polícia. Dois membros da comunidade morreram devido aos tiros da polícia e muitos outros foram feridos. Membros da comunidade, incluindo ativistas dos direitos humanos, foram detidos, torturados e acusados de terrorismo em uma estação de polícia funcionando dentro do campo de mineração. O prefeito da província foi encarcerado sem processo regular. Na capital da província, os escritórios da Fundação Tintaya - encarregados de administrar os fundos dados pela Tintaya - foram queimados por manifestantes (El_Comercio 2012; La_República 2012). As mortes em protestos devido ao uso de armas de fogo pelas forças policiais têm crescido continuamente a níveis alarmantes, em parte devido a uma recente legislação que permite o uso do exército para controlar protestos civis e faz imune de exoneração aqueles policiais que matam durante protestos (Briceno \& Bajak 2012; Silva 2012).

Através dos três seguintes exemplos relacionados à mineração em Cuzco, arranjados em ordem cronológica, discutirei sobre as diversas formas pelas quais as montanhas tomam parte nas relações entre as comunidades locais, corporações mineradoras e representantes de estado.

Primeiro exemplo: em 2000, como parte de uma visita às instalações da mina Tintaya, tive um conversa com o gerente de uma microempresa que prestava alguns serviços para a companhia mineradora. Ele era membro de uma comunidade Quechua vizinha. O contexto mais amplo era marcado por múltiplas demandas considerando os impactos negativos sofridos pelas comunidades circunvizinhas, e levou a protestos e negociações que terminaram em um importante acordo em 2003: a companhia aprovou, entre outros comprometimentos, dar 3\% de seus lucros para o desenvolvimento das comunidades (Durand 2009; Scurrah 2008).

Já em vias do fim de nossa conversa, eu estava curioso em saber como prestar serviços para a mina teria influenciado a opinião do gerente sobre a companhia. Perguntei: "você pensa que essa oportunidade de trabalho mostra que a mina pode ser um bom vizinho?". Ele me deu uma resposta curta: “A companhia [mineradora] não nos dá trabalho, a montanha [é quem] nos dá" ("La compañía no nos da trabajo, el cerro nos da"). Por essa ressalva, ele contundentemente estabelece sua posição, deslegitimando possíveis afirmações sobre efeitos positivos da companhia de mineração, atribuindo a fonte do trabalho da comunidade para a agência da montanha.

Aqui há um contexto interacional no qual é atribuído que a montanha permite que a mina opere e tome parte de seu corpo. Através do Mercado que transforma metal em dinheiro, parte do corpo da montanha produz trabalho, e parte vai para os fundos de desenvolvimento. Esse dinheiro, muito embora, precisou ser obtido por meio de protestos e negociação com a companhia mineira que media o processo extrativo. A distribuição da riqueza da montanha é deixada pela montanha para negociações entre humanos em um nível local. Essas são relações entre a comunidade local, a companhia mineira e a montanha, nas quais o governo central, instância responsável por regular as atividades mineradoras, está flagrantemente ausente. 
Segundo exemplo: em 2007 houve fortes rumores na mídia local sobre a presença de um novo projeto de mineração na área do templo Quyllurit'i, o foco da principal peregrinação da região, profundamente associada com a geleira Qulqipunku e relativamente perto de Ausangate, o mais alto e mais importante apu da região. Em um cenário amplo de fortes protestos contra a atividade mineradora, a Irmandade do Señor de Quyllurit'i, que articula centenas de trupes de dança e milhares de devotos por toda região, organizou um protesto contra o projeto. Paralisaram o centro de Cuzco tendo como principais protagonistas centenas de dançarinos se apresentando em seus trajes cerimoniais, algo não visto em uma cidade testemunha da forte mobilização no passado contra o regime de haciendas (De la Cadena 2010; Neira 1964). Este protesto também incluiu pessoas das comunidades circunvizinhas da geleira, que vieram à cidade em ônibus alugados pelo Município de Ocongate, o distrito onde o templo é localizado. Uma delas era Nazario Turpo, um conhecido especialista em mediar as relações entre humanos e lugares, que vivia perto de Ausangate, e que conversou naquela ocasião com Marisol de la Cadena. Ela conta que as razões dele para protestar eram, por um lado, proteger os pastos de sua comunidade, mas por outro lado, ele explicou que...

“Ausangate não permitiria a mina em [... uma montanha sobre qual ele presidia. Ausangate ficaria nervoso, e poderia mesmo matar pessoas. Para prevenir aquelas mortes, a mina não deveria se realizar [...] Prevenir a ira de Ausangate era a motivação de Nazario em participar na demonstração, e assim ele possuía aporte político.” (De la Cadena 2010: 339)

Essa visão era bastante diferente de como os jornais locais relataram os protestos, como sugere na seguinte manchete: “A força dos homens em defesa de Apu Qoyllur Rity”(Diario_del_Cusco 2007).

A posição de Nazario Turpo mostra um contexto em que Ausangate, o mais alto apu regional, seria abertamente contra a vontade de instituições estatais que promovem a mineração e as mineradoras. O apu estaria até disposto a usar de violência para impedir os mineradores em seu reino. Neste cenário, protestar era mediar entre estes dois poderes para que nenhuma pessoa sofresse danos pelas vontades contraditórias. Levado a cabo no centro regional de poder político humano, o protesto seguiu com a performance que tinha as autoridades mineradoras como audiência, invocando sua intervenção. Eles indexaram o âmbito da inquietação social que poderia desenrolar se um projeto de mineração afetasse o templo Quyllurit'i e, na imagem proposta por Nazario Turpo, uma tentativa de prevenir um choque entre a agência de Ausangate e a agência da companhia mineradora que potencialmente levaria à morte dos trabalhadores mineiros.

Terceiro exemplo: Havia muito preocupantes rumores da presença de mineiros na comunidade de Hapu (Paucartambo) durante 2008, em que estavam presentes em todos os lados da zona rural de Cuzco. Tive a oportunidade, enquanto realizando trabalho de campo ali, de perguntar ao povo de Habu sobre essa questão. Perguntei por que as pessoas se preocupam tanto se os apus são tão poderosos? Deixariam eles os mineiros entrarem e tomarem os metais deles?

Algumas respostas apontaram na direção de um conflito intero em Hapu. Os apus poderiam estar nervosos por causa dos convertidos evangélicos - quase metade da comunidade - que pararam de dar as oferendas de alimentos a eles. Os apus podem assim permitir a mineração para punir os evangélicos. Outras respostas apontavam as suas 
diferenças em relação aos engenheiros de mineração. Os mineiros, como eram engenheiros, sabiam muito mais que eles. Assim, poderiam dar melhores oferendas de alimento que aquelas dadas pelos membros da comunidade e os apus poderiam deixar os mineiros tirarem minerais deles. Dependendo da sofisticação das oferendas de comida, as montanhas poderiam mudar suas vontades e preferir estabelecer alianças mais favoráveis com os mineiros, sendo capazes de deixar aparte os menos sofisticados e desprotegidos humanos que dependem deles.

O primeiro tipo de resposta enquadra o comportamento potencial dos apus como reações a um conflito interno entre diferentes facções da comunidade Hapu. Neste caso, as montanhas puniriam mesmo aqueles que continuaram dando oferendas para satisfazer sua ira contra os evangélicos que se recusam a reconhecer seu poder, uma instância de sua arbitrariedade. A segunda resposta marca a atitude potencialmente favorável das montanhas para com os mineiros pelos méritos de suas oferendas e assim, a uma questão de hierarquia étnico-racial de conhecimento entre profissionais falantes de espanhol ou inglês e os camponeses rurais falantes de Quechua.

Esse caso ressalta o caráter instável e processual das relações entre humanos e lugares. As montanhas podem desconsiderar o bem-estar da comunidade nela residente quando oferendas notavelmente melhores são dadas por terceiros. Estas relações não são estabelecidas e dadas, mas precisam ser constantemente cultivadas. Quando desonradas e descuidadas, elas perdem força, ou, ainda pior, provocam a ira das montanhas, como por exemplo, a recusa evangélica em dar comida para as montanhas poderia resultar a permissão da montanha para a entrada dos mineiros. As montanhas não são entendidas como obrigadas a manter certas relações quando alianças alternativas podem oferecer melhores termos. Montanhas, similarmente aos humanos, se comportam em um mundo social em que, segundo o contexto varia e as relações de poder mudam, as alianças políticas podem ser realinhadas.

A mineração implica necessariamente um tipo de negociação com a montanha a ser minerada, pois consiste em extrair partes do corpo da montanha. Assim, não é surpreendente que engenheiros de mineração tenham de saber como negociar com as montanhas através de oferendas de comida. Isso foi relatado em outras partes dos Andes como Antabamba (Gose 1986: 303) ou Conchucos (Salas 2002: 340). Gose (1986) elabora como uma montanha minerada foi percebida como aleijada e se tornando mais e mais exigente. Tanto em Antabamba e em Conchucos, engenheiros de mineração assumiram em tomar pessoas - através de frequentes acidentes dentro das minas - como devoradas pela montanha. Em um cenário levemente diferente, Nash (1979) relata que periódicas oferendas de lhamas dadas à mina asseguraram não apenas a falta de acidentes, mas a produção de metal da montanha.

A forte oposição frente à mineração por entidades como Ausangate é facilmente entendível porque a mineração a céu aberto contemporânea - diferentemente da mineração subterrânea-pode não só destruira fertilidade da montanha como literalmente destruir a própria montanha. Dentre essa cena, o interesse comum entre o apu e os humanos que nele residem é óbvio.

Deve ser recolocado que todos esses casos mostram a ausência do Estado como um importante ator nas negociações envolvendo montanhas, companhias mineradoras e comunidades humanas. Enquanto em dois exemplos 
o Estado é ausente das interações, o outro é sobre uma performance que tenta engajar as instituições estatais a não restringir seus papéis unicamente em prover concessões de mineração, mas assumir suas responsabilidades para com as comunidades locais.

\section{MONTANHAS E SENHORES DE TERRA}

Quando conversando sobre este trabalho, Juan de Dios - o curandero urbano - se referiu a aqueles que sabem como mediar humanos e lugares poderosos com uma palavra profundamente associada ao regime de haciendas:

JdD: O pongo então tem que lhes chamar. O pongo é autorizado a chamar os anjos .

\section{A: Equem é o pongo?}

JdD: Ele é o altumisayuq, é claro. Eles rezam e chamam. E os anjos entram na mesa. Quando eles entram, você deve convidá-los a beber .

Pongo vem de punku (Quechua para porta) ou pela hispanização de punkuq (pertencente à porta), guardador de porta. Era um dos serviços que os povos Quechua vivendo em haciendas (grandes latifúndios) tinham que executar para manter seu direito de cultivo de um pequeno pedaço de terra para sua subsistência. Um pongo tinha de trabalhar por algumas semanas todo ano na casa do senhor de terras ao mais baixo status de servo. A palavra encapsula os extremos da exploração no sistema de haciendas. O estereótipo dos pongos está presente em O Sonho do Pongo, uma peça de José María Arguedas (2005). Embora não seja claro o quanto vem da interpretação do autor, ele conta em sua introdução que isso lhe foi dito em Quechua por uma pessoa em Ccatca (Quispicanchis), nos anos sessenta. Um retrato similar pode ser achado no primeiro capítulo de seu romance Ríos Profundos, publicado em 1958, tendo como cenário a casa de um senhor de terras na cidade de Cuzco:

O pongo esperou na porta. Ele tirou seu chapéu, e assim, seguiu-nos ao terceiro pátio. Ele entrou sem fazer barulho, com o cabelo atrapalhado e levantado. Eu lhe falei em Quechua. Ele me olhou em confusão.

- $\quad$ Não sabe ele como falar? - Perguntei a meu pai.

- $\quad$ Ele não se atreve - ele me contou $[\ldots]$

Ele tinha um poncho muito pequeno e surrado. Fez uma reverência e pediu licença para sair. Ele fez uma reverência como um verme pedindo para ser esmagado (Arguedas 1978).

O seguinte fragmento de uma conversa que tive com Demetrio Roca, um respeitado antropólogo de Cuzco, também é ilustrativo. Relembrando sua participação em uma pesquisa realizada em 1955, ele comentou sobre os pongos da hacienda Q'ero (Paurcartambo): 
“... faziam todas as suas obrigações pontualmente. Por exemplo, indo como pongos a Paucartambo [a capital provincial onde o senhor de terra morava] por trinta dias e lá, pobres deles! Como sofriam! Eu os encontrei morando em barracos, dormindo no chão. Não tinham nada para comer! Perguntei se recebiam comida, não recebiam. Haviam comprado alguma, mas já acabara. "Mas como vocês sobrevivem? O que comem?", "Apenas folhas de coca", me contaram." (Conversa com Demetrio Roca; Cuzco, 2004)

A Reforma Agrária lançada em 1969 levou finalmente o já fraco sistema de haciendas a seu fim. Desde então, pongos servindo como servos de humanos senhores de terras não mais existem, apenas aqueles que servem às montanhas. Juan de Dios não é a única pessoa que usou a palavra pongo desta forma. Este uso foi relatado por vários etnógrafos (ver Arguedas 1975; Favre 1967: 134; Gose 1986: 302; Morote 1956: 290).

As haciendas de Cuzco, e as terras altas andinas, foram fundadas em arranjos assimétricos recíprocos entre os colonos - aqueles que vivam e trabalhavam na hacienda - e o senhor das terras. As famílias dos colonos eram incapazes de cobrir todas suas necessidades com a produção das pequenas glebas de terra que os senhores de terra thes destinavam. Tudo que era necessário para a reprodução da família e da comunidade, e que eles não conseguiam pagar, era provido pelo senhor das terras como supostos atos de generosidade. O senhor era o dono das terras, um provedor para a reprodução social da comunidade e o juiz supremo da ordem moral da hacienda. Punição física dos colonos era disposta como a correção de crianças por seu pai responsável (Anrup 1990; Orlove 1977; Skar 1988). De fato, senhores de terra rotineiramente eram chamados de papay ("meu pai"). Assim, os senhores assumiram o papel de generosos e responsáveis pais para "seus índios" enquanto também sendo ferrenhos castigadores.

O uso do termo pongo para se referir a curanderos ou paqus nos conta sobre as relações de poder entre os humanos e as montanhas. A similaridade entre senhores de terras e as poderosas montanhas vai além do uso dessa palavra. Por exemplo, nos anos sessenta, uma pessoa da área do Rio Pampas (Ayacucho) contou a John Earls que as montanhas de poder poderiam

“... aparecer em forma humana montando "em um belo cavalo, luxuosamente aparelhado com uma sela nobre, e uma capa de sela de San Pedrano, com rebites de prata - toda completa. Ele usa um belo poncho, poncho pallay daqueles antigos, muito fino e com apetrechos; ele se assemelha àqueles fazendeiros ricos (hacendados)".

Afirmações similares sobre aparições de apus foram relatadas por Gose (1986: 299) em Antabamba (Apurimac) no fim dos anos setenta. Da mesma forma, montanhas de poder tendiam a ser caracterizadas como misti - uma categoria relacional étnica referente estereotipicamente a residentes da cidade e falantes de espanhol urbanos - $\mathrm{e}$ racializadas como homens brancos, altos e barbados (Ansion 1984: 138-9; Earls 1969: 67; Gose 1986: 286; Rosalind Gow \& Condori 1976: 52; Rasnake 1988: 257; Sallnow 1987: 130; Tomoeda 1992: 229).

Montanhas controlam os meios de produção dos humanos, particularmente dos pobres que dependem da agricultura. Assim o poder das montanhas é experimentado como similar ao dos senhores de terra da mesma maneira 
que usam de luxuosas roupas similares, e são vistos como racialmente similares enquanto brancos. São vistos como poderosos pais e castigadores frios, em larga escala, ambos eram vistos como detentores da vida e da morte. Gose (2008) sustenta que a raça branca das montanhas é outra instância de uma estratégia andina de longue durée de se apropriar do poder daqueles que os dominam. Como será explicado na próxima sessão, essas similaridades não necessariamente significaram que as montanhas seguiram politicamente os senhores de terra.

\section{VICUÑAS E TRIBUTOS}

Alguns trabalhos etnográficos realizados antes da ReformaAgrária(1969) incluíam informações fragmentárias sobre como as pessoas se referiam às relações entre as montanhas e as instituições estatais. Levando em consideração as perspectivas muito limitadas que podem dar destes relacionamentos, eu os uso para propor um padrão de mudanças nas formas como as pessoas experimentaram as montanhas se relacionando com o Estado.

Bernard Mishkin, que efetuou trabalho de campo com a comunidade de Kawri (Quispicanchis) no fim dos anos trinta, relatou: "é dito que o apu Ausangate é responsável pela legislação aprovada da capital proibindo a matança de vicunhas e o uso de sua lã para tecelagem" (Mishkin 1940: 237). Um tema similar é mencionado por Gregorio Condori, uma falante Quechua que foi porteiro do mercado de Cuzco. Ele se lembra, no início dos anos setenta, das histórias que ouviu de outros colegas de cela Quechua de quando esteve arbitrariamente preso, nos anos quarenta:

Eu ouvi sobre como o apu Ausankati percorreu todo o caminho até Lima para conversar com o governador, em sua própria casa. Para a ocasião, o apu foi vestido em suas melhores roupas, que eram lindas e feitas de ouro puro. Ele entrou na casa do governador reluzindo e brilhando, e como aquele tipo de vestimenta não pode ser achado em lugar algum, até mesmo o governador invejou as roupas do apu, dizendo: "muito bonitas!".

Mas o apu fora para dizer ao governador que sua polícia e seus compadres estavam matando vicunhas, e que se continuasse com isso, ele iria levar todas suas vicunhas para dentro da montanha Ausankati, e não haveria mais vicunhas em solo peruano.

Mais tarde, eu pensei sobre como não há mais vicunhas hoje. Eu ouvi que todas desapareceram. É porque o governador não disse aos policiais para parar de matar as vicunhas. Ou talvez eles foram ditos e ignoraram? De qualquer forma, o apu Ausankati deve ter ficado realmente irado e pastoreou as suas vicunhas para longe. É por isso que não há mais nenhuma vicunha em solo peruano agora (Valderrama \& Escalante 1996: 62-3).

Aqui, a geleira de Ausangate e o governador são diferentes pessoas que possuem diferentes e desiguais esferas de poder. O poderoso apu Ausangate não pode impedir os policiais do governador e sua clientela de matarem seus rebanhos. Ele precisa ir a Lima e negociar o assunto com o governador. No fim, na avaliação de Gregorio, o apu falhou em colocar pressão suficiente sobre o governador e teve que retirar seus rebanhos para poder protegê-los.

Earls (1969) nos provê com a elaboração mais coerente deste tema. Ele relata como uma pessoa de San Miguel 
(Ayacucho), nos anos sessenta, identificou as montanhas com a burocracia estatal. Aqui, a questão da caça de vicunhas também aparece. Wamani é usado em Ayacucho similarmente em como foi apu utilizado em Cuzco.

Os Wamanis são diretamente engajados ao serviço do governo da República do Peru. Nas palavras de um informante da comunidade de San Miguel, "quando problemas surgem entre os Yayas [pais] (Wamanis) sobre gado ou outra coisa, eles se vestem como mistis e aparecem diretamente ao presidente da república para resolvê-los.” [...] "No mês de agosto, [as montanhas] abrem suas portas e consultam entre si para mandar suas riquezas (ouro e prata) para o governo, e isto eles fazem usando vicunhas e viscachas [Lagidium peruanum] como animais de carga que transformam em burros e mulas. Carregam através das montanhas em direção à costa. Eu não sei como as entregam, mas é para o governo". "vez que as vicunhas e viscachas são seus animais de carga, quando os caçadores estavam extinguindo estes animais, os Wamanis reclamaram com o governo e esse é o motivo pelo qual este último proibiu a caça de tais animais; eles até mesmo punem os caçadores colocando-os em prisões."

As próprias oferendas que os índios fazem para seus [...] Wamanis, são o material bruto do qual o ouro e a prata são feitos para serem mandados ao governo em Lima, e informantes mais sofisticados relatam que os Wamanis possuem maquinário dentro das montanhas para a feitura disto. À luz deste ponto de vista, não deveria ser surpresa que os Wamanis aparecem em forma de policiais para forçarem a feitura de oferendas para eles. Em uma variante do sistema, os menores Wamanis enviam seus tesouros primeiro a seus chefes, e estes os mandam para Rasuwillka e Qarwarasu, as duas montanhas “capitais”, que negociam diretamente com o governo na entrega (Earls 1969: 69-70).

Aqui as montanhas não são apenas hierarquicamente organizadas entre elas, mas, mais importante, são subordinadas ao Presidente da República e ocupando funções de coletores de impostos para o governo. As oferendas de comida não são unicamente retribuições recíprocas para as montanhas, mas constituem a matéria bruta do ouro e prata das montanhas. Assim, o oferecimento de comida terminou por se transformar em tributos enviados ao governo. O poder do Estado e das montanhas segue a mesma lógica e, em última instância, está sob a autoridade do presidente. Aqui existe um poderoso Estado que demanda a obediência mesmo das montanhas. Paradoxalmente, através de oferendas de comida para as montanhas, essas comunidades também foram estabelecendo relações de reciprocidade assimétrica com o governo, o poderoso agente à frente das formais instituições estatais (um similar, embora mais curto, relato foi feito por Isbell 1978: 59).

Houve outros contextos nos quais as montanhas intervieram em atividades reguladas pelo Estado. Elas se importam por seus protegidos, mas não questionam a legitimidade dessas instituições. Por exemplo, Roel (1966: 26) relata que o apu Qontonya (Chumbivilcas) protegeu as suas crianças humanas do serviço militar provocando nelas algumas doenças para que fossem expulsas do exército. No mesmo trabalho, ele relata como algumas montanhas podem ser particularmente efetivas intervindo em processos judiciais (Roel 1966: 27).

Todos estes contos fragmentários surgem em contextos onde as autoridades do Estado estiveram largamente em favor dos interesses dos senhores de terra, sendo em muitos casos a mesma pessoa ou parentes próximos (Poole 
1988; Skar 1988: 244-247). Isso envolveu a intervenção do exército defendendo os interesses dos senhores de terra como lembra Bernabé Condori, nos anos setenta, sobre as lutas de seu povo contra os senhores de terras de Lauramarca e Pinchimuro, nos anos cinquenta:

Então vieram os soldados e nos caçaram. Nossas mulheres dormiram nas montanhas porque os soldados as procuravam [...] Os soldados atiravam seus rifles e as mulheres os assustavam com suas fundas. Os soldados levaram todos nossos animais para a porta da hacienda Pinchimuro. Ali, eles abateram nossas vacas. Tiraram nossas roupas, e as usaram para enrolar [a carne], nos fizeram cozinhar para eles.

Nós não podíamos mais aguentá-los. Nos juntamos de Pinchimuro e Lauramarca, dizendo 'nós morreremos mas eles não conseguirão matar todos nós', nós todos nos juntamos com um coração. Dissemos, 'não temos medo da morte'. Nas planícies de Qallawasi, todo o povo de Lauramarca e Pinchimuro lutou contra os soldados. Eles mataram Fortunato Merma. Tiros passavam por nossas cabeças. Nós derramamos muito sangue (Gow \& Condori 1976: 32-3, minha tradução).

O povo em Pinchimuro e Lauramarca claramente viu o poderoso apu Ausangate lutando a seu lado contra os senhores de terras. As conversas de Rosalind Gow (1982: 200) com diferentes líderes são muito explícitas. Um disse “o Apu disse aos nossos antepassados: 'vocês devem lutar contra o hacendado. Um dia haverá justiça”'. Outro afirma que "Apu Ausengate sempre nos ajudou como nosso advogado e amigo legítimo". Um terceiro, usando da retórica esquerdista da época, afirma “o Apu Ausangate lutou por nós como nosso irmão revolucionário". Ainda, ela relata que pelo menos quinze líderes políticos de Lauramarca e Pinchimuro também eram paqus, pessoas que sabem como se comunicar com montanhas de poder. Ela mostra que eles não viam contradição entre essas funções, mas que seriam bons líderes porque eram bons paqus (Rosalind Gow 1982: 201, 216; esse é o caso central do livro de De la Cadena’s [2011] a ser publicado). Esse tipo de intervenção das montanhas tende a ser excepcional na bibliografia etnográfica(ver a discussão de Gose [1994: 240-3]).

As comunidades Quechua demonstram contínuos esforços em recorreràs instâncias estatais para melhorar suas condições. Embora "o governo" tende a ser visto como uma pessoa e equivalente ao presidente, essas comunidades negociam com múltiplas instâncias e agentes e foram capazes de estabelecer alianças com alguns deles, bem como partidos políticos, organizações estudantis ou sindicatos (Heilman 2010; Kapsoli 1977). O repetido apelo ao judiciário e aos grandes poderes fundiários são apenas dois exemplos da seriedade com que essas comunidades confrontaram-se com instâncias estatais (Ansion 1984: 159; Gose 1994: 247).

\section{DIFERENTES ESFERAS DE PODER}

Lançada em 1969, a reforma agrária foi levada a cabo durante a primeira metade dos anos setenta pelo regime militar populista e reformista liderado por Juan Velasco (ver Mayer 2009; Seligmann 1995; Skar 1988). Escolho a reforma agrária como um divisor de águas devido a sua relação com o fim do regime de haciendas nas terras altas 
peruanas. Muito embora deva ser claro que as mudanças que tomaram parte no campo não seguem um corte claro entre antes e depois da reforma agrária. O regime de haciendas já estava fraco no campo peruano e a própria reforma foi uma resposta a um campo mobilizado desde os anos vinte, mas mais notavelmente durante os anos sessenta (Kapsoli 1977; Neira 1964; Rénique 1991). Depois da reforma, a guerra interna foi ligada a uma progressiva fragmentação das organizações políticas e do poder estatal. Existe uma diferença radical entre a atual fragilidade e pobre articulação dos diferentes níveis do governo (municipal, regional e nacional) e o monolítico e ubíquo Estado militar no início dos anos setenta.

As relações entre montanhas e instâncias estatais passaram por transformações quando a terra deixou de ser controlada pelos senhores de terras, a rede de migração se torna mais densa, a mobilidade entre áreas urbanas e rurais é mais fluida, povos indígenas adquirem o direito ao voto e os prefeitos distritais e provinciais passaram a ser democraticamente eleitos. Enquanto essas mudanças democráticas tomam parte ao longo do século XX, o modo como as pessoas experimentam o comportamento das montanhas também muda.

Como mostram os testemunhos de Lauramarca e Pinchimuro, houveram situações em que montanhas foram vistas contra os senhores de terra antes de 1969. Como resultado da reforma, os apus foram tidos mais claramente por aliados das comunidades. Como uma pessoa de Qamawara (Calca) contou a Sallnow (1987: 129), no fim dos anos setenta, "entre aqueles que nos trazem justiça estão nossos apus, que são muitos".

Nos primeiros anos da guerra interna, Ansion (1984: 154-6) gravou uma narrativa de uma mulher que viveu sua juventude em Huamanquiquia (Ayacucho), que é relevante para nossa discussão: depois que uma autoridade comunal, Valentin Wamani, estabeleceu uma relação favorável com a montanha Pirwachu, esta apoiou a tentativa da comunidade de se tornar um distrito. Pirwachu providenciou os recursos para uma viagem e um presente de ouro a ser dado, com a petição, ao presidente. Isso impressionou o presidente e ele aprovou o pedido da comunidade. Mas ele enviou a polícia para levar Pirwachu a sua presença. No entanto, a polícia foi capaz apenas de capturar a sua 
cabeça, Valentín Wamani, enquanto que o corpo estava incorporado pela montanha, o que Ansion interpreta como uma referência às redes migrantes em Lima. Ansion ressalta que o sobrenome da autoridade refere-se ao título da montanha (Wamani) enquanto seu nome ressoa como "valente". Isso contribui com uma forte referência à emergência relacional de uma sociedade de humanos e lugares na conjunção de ambos os tipos de seres na personalidade de sua autoridade. Lorde Pirwachu faz possível a aquisição da comunidade da montanha de um maior status dentro da estrutura hierárquica da jurisdição do Estado. Aqui, Pirwachu não está a serviço do presidente. Bem o contrário, ele é visto como uma ameaça ao poder do presidente.

Penelope Harvey (1991) mostra que durante os aos oitenta, o povo da cidade de Ocongate (Quispicanchis), em sua maioria bilíngue, percebia o poder das montanhas como em oposição e em tensão com o poder do Estado. As montanhas eram retratadas pelos Quechua enfatizando "similitudes em modo de vida e substância corporal entre si mesmos e esses seres" (1991: 6). Além das diferenças de status, as pessoas eram ambíguas em seu alinhamento com tais poderes. Em alguns contextos as montanhas eram exaltadas como a fonte da fertilidade e os modelos de reciprocidade, enquanto o mundo hispânico era enquadrado como arbitrário e explorador; em outros, as montanhas eram apresentadas como primitivas em poder e modo de vida, e o mundo hispano falante era associado com altos valores de educação formal e tecnologia sofisticada. Mesmo que o poder das montanhas não fosse concebido como uma força que poderia emancipar os povos falantes de Quechua da hegemonia do mundo falante de espanhol, também não era mais um poder a serviço do Estado.

As mudanças nas aparições das montanhas parecem um processo maior, como pode ser visto no seguinte fragmento de minhas conversas com Juan de Dios:

$\mathrm{JdD}: \quad$... eles se apresentam como camponeses, possuem muitos trajes de camponeses diferentes.

\section{A: $\quad$ Como é Pikul?}

JdD: Ele é um camponês também.

\section{A: $\quad$ EAusangate?}

JdD: Ausangate é um camponês, como um poncho alto e calças curtas até os joelhos, com um pequeno chullo [pequeno boné tricotado], com um pequeno cachecol.

\section{A: $\quad$ E quem não aparece como camponês?}

JdD: Todos [aparecem como camponeses]. O único que aparece como um padre é o querido pai Pachatusan [...] O querido pai Urusaywa é um medico, às vezes vem com roupas de médico, às vezes com uniformes militares.

A: Por que? Ele é um soldado também? 
JdD: Acontece que ele é um soldado também.

A: E o que ele faz como um soldado? O que você lhe pede para fazer?

JdD: Defender, é claro. Defender de delinquentes, de roubos.

A: $\quad$ Ah, esse tipo de coisas.

JdD: Agora, o querido pai Santo Domingo de Quillabamba também aparece como um padre.

A: E existe alguém que aparece como um advogado ou um senhor de terras?

JdD: Eles entram dessa forma, Saqsaywaman, Pikul, por vezes entram usando ternos, por outras como camponeses, de diferentes formas.

Juan de Dios não viuas montanhas como senhores deterras em seus sonhos. Antes, as viu em roupas efunções de profissionais da sociedade contemporânea: médicos, oficiais do exército, advogados, e mesmo padres. A proeminência destes profissionais segue a ideologia que vê a educação formal espanhola como organizadora de hierarquias legítimas. Mais surpreendente é que todas as montanhas de poder usam o que Juan de Dios chama de 'roupas de camponeses', roupas tradicionais estereotípicas dos Quechuas rurais. Atualmente essas roupas são dificilmente utilizadas pelos próprios Quechua rurais, exceto por certas autoridades de comunidades das terras altas em celebrações oficiais (e.g. os portadores dos bastões das comunidades de Pisaq quando executando atividades oficiais; ver Pérez 2005), e outras pessoas, ou até eles mesmos, executam representações estereotípicas dos índios pré-modernos em danças que são enquadradas como interpretações etnográficas e realizadas em celebrações cívicas da região, do distrito, ou mesmo da escola. Então, as roupas dos apus se tornaram mais ambíguas, por um lado apelando ao poder da educação profissional e, por outro, à representação estereotípica da autenticidade indígena. 
De acordo com as afirmações de Juan de Dios, as montanhas continuam a intervir nas atividades da burocracia estatal:

JdD: Eles entram [...] nas cortes. Quando realmente se tem fé, eles entram, encarnados, você vê uma pessoa [...]

A: Sério?! E o que eles fazem?

JdD: Eles apagam seus registros, fazem se perder, as assinaturas desaparecem...

A: $\quad[\ldots]$ Quem faz isso? Qual apu faz isso?

JdD: É claro que qualquer apu pode fazer isso. Só depende de seu pedido.

Os apus não intervêm para fazer com que os juízes sigam a lei. Antes, eles se comportam de acordo com a prática social que prediz como processos judiciais são vencidos: desaparecendo evidências, falsificando assinaturas e usando outras práticas arbitrárias similares. Enquanto humanos com suficiente dinheiro ou influência podem ganhar processos judiciais recorrendo a estas práticas, de acordo com Juan de Dios, aqueles que "realmente têm fé" podem contar com o poder das montanhas para alcançar fins similares.

Em uma grande escala, as formas pelas quais humanos relacionam com montanhas de poder são similares a como a maioria das pessoas experimenta suas relações com instituições estatais. Os escritórios públicos são primeiramente assumidos como fontes de poder individual, e aqueles que os mantêm tendem a exercer seu poder de formas clientelistas. É necessário relacioná-las através de formas assimétricas de reciprocidade-dado o presente certo dado por Pirwachu ao presidente-de modo a alcançar o resultado desejado.

\section{CONCLUSÕES}

Focalizei as formas pelas quais as montanhas se relacionam com outros agentes poderosos, particularmente burocratas estatais e autoridades, e companhias mineradoras. Antes da reforma agrária, o poder das montanhas e aquele dos senhores de terras pareciam entre si. Montanhas e senhores de terras eram vistos usando roupas similares, possuindo os mesmos fenótipos, e ambos eram generosos provedores e frios castigadores. Em certo sentido, montanhas podem ser vistas, mesmo atualmente, como senhores de terras, porque provêm os lugares para o cultivo e a residência, e podem retirar sua fertilidade de acordo com suas decisões arbitrárias. Pessoas que dependem das montanhas estão em posição de forte inferioridade. No entanto, nem todos os humanos então sujeitos à dependência. Tecnologias atuais de mineração mostram como outros humanos, que podem depender de outros lugares, podem destruir não somente a fertilidade, mas as próprias montanhas, o que é mostrar a hierarquia entre mineiros e camponeses.

Antes da reforma agrária, quando as montanhas retinham algumas esferas de influência, seu poder era inferior ou mesmo subordinado àquele do presidente ou do governador. Entrelaçadas em relações de poder, as montanhas interviram nas esferas judiciais do Estado, ou em esforços das comunidades para construir alianças com burocratas em 
sua luta contra o regime dos senhores de terras.

Atualmente, as montanhas não lembram senhores estereotípicos, mas antes são tomadas como profissionais urbanos e também como povos indígenas estereotipificados. Seu poder é mais claramente independente das instituições do Estado e tende a se opor a elas. No cenário atual, embora as montanhas não possam mudar as regras da esfera do Estado, elas podem intervir nele, mudando as relações de poder para beneficiar seus protegidos humanos.

O boom da mineração mostra claramente essas mudanças. Montanhas podem ser abertamente contrárias ao Estado, podem negociar suas relações com companhias mineradoras sem a interferência estatal, tomando diferentes posições frente às comunidades que delas dependem. Em altos níveis de contaminação, como em Cerro de Pasco (Geen et al. 2012), ou na mineração a céu aberto, a fertilidade das montanhas pode ficar seriamente danificada, e elas mesmas podem ser literalmente destruídas.

Ao passo que as intervenções políticas das montanhas se mostram mais e mais visíveis para a esfera pública, elas tende a ser confundidas como manipulação de líderes astutos sobre pessoas ignorantes, ou como românticos absurdos ambientalistas. As disciplinas dominantes de conhecimento, a fundação política formal, a mídia dominante nacional e internacional, não conseguem aceitar que práticas indígenas que mediam as relações com montanhas se elas não estiverem ligadas à “cultura” ou a "crenças" (que estão em última instância erradas). Essas práticas só são permitidas quando em conformes para o consumo turístico. Dentro desta invisibilidade e silenciamento por parte dos setores dominantes - quebrados por alarmantes notícias de protestos - as sociedades de humanos e lugares nos Andes sul peruanos continuam a reproduzir a si mesmas, mudando suas práticas e alianças políticas de acordo com seu profundo envolvimento com cenários sociopolíticos mais amplos.

Versão em português: Christian Crevels 


\section{BIBLIOGRAFIA}

ABERCROMBIE, T. A. 1998. Pathways of memory and power : ethnography and history among an Andean people. Madison: University of Wisconsin Press.

ALLEN, C. J. 1988. The hold life has : coca and cultural identity in an Andean community. Washington: Smithsonian Institution Press.

ANRUP, R. 1990. El taitay el toro : en tomo a la configuración patriarcal del régimen hacendario cuzqueño. Stockholm: Universidad de Estocolmo.

ANSION, J.-M. 1984. Demons des Andes : la pensée mythique dans une région des Andes péruviennes (Ayacucho). Louvain-la-Neuve: CIACO.

ARGUEDAS, J. M. 1975. Puquio, una cultura en proceso de cambio. In Formación de una Cultura Nacional Indoamericana. Mexico: Siglo Veintiuno.

1978. Deep rivers. Austin: University of Texas Press.

2005. The Pongo's Dream. In The Peru reader (eds) O. Starn, C. I. Degregori \& R. Kirk. Durham: Duke University Press.

BEBBINGTON, A., D. HUMPHREYS BEBBINGTON, J. BURY, ET AL. 2008. Mining and Social Movements: Struggles Over Livelihood and Rural Territorial Development in the Andes. World Development 36, 2888-2905.

BLASER, M. 2009. Political Ontology. Cultural Studies 23, 873-896.

BLOOMBERG 2011. Pan Pacific Copper to Start Quechua Mine in 2014 (available on-line: http://www.bloomberg. com/news/2011-01-03/pan-pacific-copper-to-start-quechua-mine-in-2014-gestion-says.html, accessed 1 March 2013).

BRICENO, F. \& F. BAJAK 2012. Peru's Anti-Riot Tactics Unmatched in Lethality. The New York Times, July 14.

DE LACADENA, M. 2010. Indigenous cosmopolitics in the Andes: Conceptual reflections beyond 'Politics'. Cultural Anthropology 25, 334-370.

2011. Alternative Archives: Indigenous Politics the Andean Way (provisional title). Unpublished manuscript.

CHAKRABARTY, D. 2000. Provincializing Europe: postcolonial thought and historical difference. Princeton: Princeton University Press.

CHIRIF, A. 2011. Perú: ¿En qué cree el señor presidente? Servindi (available on-line: http:/servindi.org/ 
actualidad/47380, accessed 23 November 2012).

COOPERACCIÓN 2010. Informe de seguimiento de las Concesiones Mineras en el Perú - Región Cusco. Lima: CooperAcción.

DALLE, L. 1969. El Despacho. Allpanchis 1, 139-154.

DEFENSORÍA-DEL-PUEBLO 2010. Reporte de Conflictos Sociales 77, julio 2010. Lima: Adjuntía para la Prevención de Conflictos Sociales y la Gobernabilidad.

2012. Reporte de Conflictos Sociales 100, junio 2012. Lima: Adjuntía para la Prevención de Conflictos Sociales y la Gobernabilidad.

DESCOLA, P. 2005. Par-delà nature et culture. Paris: Gallimard.

DIARIO_DEL_CUSCO 2007. Fuerza de los hombres en defensa del Apu Quyllur Rity. Diario del Cusco, March 6.

DURAND, F. 2009. Tintaya y su gobierno minero. Quehacer 173, 27-37.

EARLS, J. 1969. The organisation of power in Quechua mythology. Journal of the Steward Anthropological Society $1,63-82$.

DE ECHAVE, J. 2005. Mining Activity and Community Rights. Lima: Cooperacción.

EL_COMERCIO 2012. Enfrentamientos en Espinar dejan dos civiles muertos. El Comercio, May 28.

FAVRE, H. 1967. Tayta Wamani: Le Culte des Montagnes dans le Centre Sud des Andes Péruviennes. Colloque D’Études Péruviennes 61, 121-140. 
FERNÁNDEZ, G. 1997. Entre la repugnancia y la seducción: ofrendas complejas en los Andes del Sur. Cuzco: CBC.

FUENZALIDA, F. 1980. Santiago y el Wamani: Aspectos de un culto pagano en Moya. Debates en Antropología 5, $155-187$.

GAMIO, G. 2011. El extirpador de idolatrías. Revista Ideele (available on-line: http://www.revistaideele.com/idl/ node/1068, accessed 25 November 2012).

GARCIA, A. 2011. Alan Garcia contra las ideologias absurdas panteistas. Mira Quien Habla (available on-line: http:// youtu.be/2Vf4WfS5t08, accessed 30 October 2012).

GEEN, A. VAN, C. BRAVO, V. GIL, S. SHERPA \& DARBY JACK 2012. Lead exposure from soil in Peruvian mining towns: a national assessment supported by two contrasting examples. Bulletin of the World Health Organization 90, 878-886.

GOSE, P. 1986. Sacrifice and the Commodity Form in the Andes. Man 21, 296-310.

1994. Deathly waters and hungry mountains: agrarian ritual and class formation in an Andean town. Toronto: University of Toronto Press.

2008. Invaders as ancestors : on the intercultural making and unmaking of Spanish colonialism in the Andes. Toronto: University of Toronto Press.

GOW, D. 1980. The roles of Christ and Inkarri in Andean religion. Journal of Latin American lore 6, 279-96.

GOW, R. 1982. Inkarri and Revolutionary Leadership in the Southern Andes. Journal of Latin American Lore 8, $197-$ 223.

GOW, R. \& B. CONDORI 1976. Kay Pacha. Cuzco: CBC.

HARRIS, OLIVIA 1980. The Power of Signs: Gender, Culture and the Wild in the Bolivian Andes. In Nature, culture, and gender (eds) C. P. MacCormack \& M. Strathern, 70-94. Cambridge; New York: Cambridge University Press.

HARVEY, P. M. 1991. Drunken Speech and the Construction of Meaning: Bilingual Competence in the Southern Peruvian Andes. Language in Society 20, 1-36.

HEILMAN, J. P. 2010. Before the Shining Path : politics in rural Ayacucho, 1895-1980. Stanford: Stanford University Press.

HUDBAY 2013. Constancia (available on-line: http://www.hudbayminerals.com/English/Our-Business/ Development/Constancia/defaultaspx, accessed 25 February 2013). 
ISBELL, B. J. 1978. To defend ourselves : ecology and ritual in an Andean village. Austin: University of Texas Press.

KAPSOLI, W. 1977. Los movimientos campesinos en el Perú, 1879-1965. Lima: Delva Editores.

KEANE, W. 2007. Christian moderns : freedom and fetish in the mission encounter. Berkeley: University of California Press.

LA_REPÚBLICA 2012. Protesta en Espinar degeneró en muertes. La República, May 29.

LATOUR, B. 1993. We have never been modern. Cambridge: Harvard University Press.

2011. From Multiculturalism to Multinaturalism: What Rules of Method for the New Socio-Scientific Experiments? Nature+Culture 6, 1-17.

MANNHEIM, B. \& G. SALAS 2013. Wak'a: Entifications of the Andean Sacred. In The Archaeology of W'akas: Explorations of the Sacred in the pre-Columbian Andes (ed) T. Bray. Boulder: University of Colorado Press.

MARTÍNEZ, G. 1983. Los dioses de los cerros en los Andes. Journal de la Société des Américanistes 69, 85-115.

MAYER, E. 2009. Ugly stories of the Peruvian agrarian reform. Durham: Duke University Press.

MISHKIN, B. 1940. Cosmological ideas among the Indians of the southern Andes. Journal of American folk-lore 53, 225-241.

MORISSETTE, J. \& L. RACINE 1973. La hierarchie des wamani: essai sur la pensee classificatoire quechua. Recherches amerindiennes au Quebec 3, 167-188.

MOROTE, E. 1956. Espíritus de Montes. Letras 56, 288-306. 
NASH, J. C. 1979. We eat the mines and the mines eat us : dependency and exploitation in Bolivian tin mines. New York: Columbia University Press.

NEIRA, H. 1964. Cuzco: Tierra o Muerte. Lima: Problemas de hoy.

ORLOVE, B. S. 1977. Inequality among peasants. The forms and uses of reciprocal exchange in Andean Peru. In Peasant livelihood: studies in economic anthropology and cultural ecology (eds) R. H. Halperin \& J. Dow, 201-214. New York: St. Martin’s Press.

POOLE, D. 1988. Landscapes of power in a cattle-rustling culture of southern Andean Peru. Dialectical anthropology $12,367-398$.

RASNAKE, R. N. 1988. Domination and cultural resistance : authority and power among an Andean people. Durham: Duke University Press.

RÉNIQUE, J. L. 1991. Los sueños de la sierra : Cusco en el siglo XX. Lima: CEPES.

REVESZ, B. \& A. DIEZ 2006. El triángulo sin cúpula (o los actores desregulados en los conflictos mineros). In Perú Hoy, nuevos rostros en la escena nacional (ed) E. Toche, 49-88. Lima: DESCO.

RICARD, X. 2007. Ladrones de sombra: el universo religioso de los pastores del Ausangate. Lima, Cuzco: IFEA, CBC.

ROEL, J. 1966. Creencias y practicas religiosas en la provincia de Chumbivilcas. Historia y cultura 2, 25-32.

SALAS, G. 2002. Jóvenes, animales y monstruos en las punas sanmarquina. Algunos motivos de la tradición oral de Conchucos. Anthropologica 20, 333-350.

2012. Negotiating Evangelicalism and New Age tourism through Quechua ontologies in Cuzco, Peru. Ann Arbor: Doctoral dissertation. University of Michigan.

SALLNOW, M. J. 1987. Pilgrims of the Andes : regional cults in Cusco. Washington, D.C.: Smithsonian Institution Press.

SCURRAH, M. 2008. Defendiendo Derechos y Promoviendo Cambios: El estado, las empresas extractivas y las comunidades locales en el Peru. Lima: IEP, Oxfam International.

SELIGMANN, L. J. 1995. Between reform \& revolution: political struggles in the Peruvian Andes, 1969-1991. Stanford: Stanford University Press.

SILVA, R. 2012. Ni un muerto más. La República, June 24. 
SKAR, H. O. 1988. The warm valley people : duality and land reform among the Quechua Indians of highland Peru. (2nd edition). Gèoteborg: Gèoteborgs etnografiska museum.

TOMOEDA, H. 1992. Mestizos y curanderos. Salud y ritual en el Cusco contemporáneo. In 500 Años de Mestizaje en los Andes (eds) H. Tomoeda \& L. Millones, 221-231. Lima, Osaka: Museo Etnológico Nacional del Japón.

VALDERRAMA, R. \& C. ESCALANTE 1996. Andean Lives: Gregorio Condori Mamani and Asunta Quispe Huamán (trans P. H. Gelles \& Gabriela Martínez). University of Texas Press.

VIALE, C. 2011. Generación, distribución y uso de la renta gasífera y minera en Cusco. Lima: Grupo Propuesta Ciudadana.

VIVEIROS DE CASTRO, E. 1998. Cosmological deixis and Amerindian perspectivism. The Journal of the Royal Anthropological Institute 4, 469-488.

2004. Perspectival Anthropology and the Method of Controlled Equivocation. Tipit'1: Journal of the Society for the Anthropology of Lowland South America 2, 3-22.

XSTRATA 2012. Our operations. Xstrata Copper (available on-line: http://www.xstratacopper.com/EN/Operations/ Pages/Operations.aspx, accessed 14 August 2012). 